\title{
Inclusive Education Reform In Mentawai Islands Cooperation for Teachers
}

\author{
$\left.\operatorname{Irdamurni}^{*}\right)^{1}$, Mega Iswari ${ }^{2}$, Asep A Sopandi ${ }^{3}$, Johandri Taufan ${ }^{4}$, Yarmis Hasan $^{5}$ \\ ${ }^{12345}$ Universitas Negeri Padang \\ ${ }^{*)}$ Corresponding author, $\equiv$ irdamurni@fip.unp.ac.id
}

Revisi 08/11/2019;

Diterima 05/12/2019;

Publish 10/01/2020

Kata kunci: Reform, Inclusive Education, Elementary and extra ordinary school teacher

\begin{abstract}
Abstrak
Reforms on inclusive education began to be carried out in Tua Pejat area, North Sipora District, Mentawai Islands by conducting training on the implementation of inclusive education by Padang State University lecturers in the context of carrying out community service for special education lecturers, followed by elementary school teachers from six elementary schools and special school teachers from two special schools in the North Sipora subdistrict of the Mentawai islands. The training was conducted with a question and answer lecture method, accompanied by a demonstration simulation method and assignments on developing a learning plan (RPP) in an inclusive class, namely modified lesson plans and modified lesson plans adapted to the characteristics and learning needs of children with special needs in the classroom. The results of the training show that collaboration between elementary and high school teachers is established, both by collaborating and cooperating in serving children with special needs in primary schools, where ing to assist elementary school teachers in matters related to the identification and assessment of children with special needs in inclusive schools, as well as working together in developing lesson plans and PPI for children with special needs in inclusive classes, and learning strategies in inclusive settings.
\end{abstract}

\section{PENDAHULUAN}

Pendidikan inklusif merupakan salah satu upaya yang dilakukan pemerintah dalam memberikan pemenuhan hak belajar bagi seluruh warga negara Indonesia, begitupun bagi anak berkebutuhan khusus. Dengan sistem pendidikan inklusif ini diharapkan tidak ada lagi tembok pemisah antara anak berkebutuhan khusus dengan anak normal dalam mengenyam pendidikan. Kepulauan Mentawai merupakan salah satu daerah yang belum menyelenggarakan pendidikan inklusif, Irdamurni \& Rahmiati 2015, menyatakan pendidikan inklusif merupakan sistem layanan pendidikan yang mempersyaratkan agar semua anak berkelainan dilayani di 
sekolah-sekolah terdekat, di kelas reguler bersama-sama teman seusianya. Dimana pembelajarannya di sesuaikan dengan kebutuhan belajar anak berkebutuhan khusus.

Hasil wawancara dengan guru sekolah dasar yang ada di kecamatan Sipora Utara , bahwa guru -guru belum memahami tentang pendidikan inklusif, dan bagai mana pelaksanaan pendidikan inklusif. Tetapi mereka sudah menerima anak berkebutuhan khusus di sekolahnya, seperti anak dengan kesulitan belajar, anak autis dan anak dengan gangguan pendengaran, pelaksanaan pembelajaran di samakan saja dengan anak regular lainnya. Hal tersebut berlawanan dengan pendapat CSIE, 2005. Selain itu konsep dasar paradigm pendidikan inklusi adalah "differentiates education for this diversity " dalam prakteknya terjadi perubahan radikal baik pada tataran konseptual maupun operasionalnya. inklusi membutuhkan format belajar yang berbeda, metode yang berbeda, dalam mengelompokkan anak dan dalam kegiatan pembelajaran pun dibedakan. Bahkan pada saat membuat perencanaan pembelajaran, hasil yang hendak dicapai pun dibuat berbeda. Elizabeth Burgwin dari UK merupakan salah seorang pionir pendidikan inklusi. Burgwin, misalnya tertarik untuk menemukan cara menggabungkan anak-anak yang cacat ke dalam sekolah biasa (normal)dengan cara menyesuaikan dengan lingkungan.

Walaupun sampai sekarang penyesuaian terhadap lingkungan fisik tersebut masih tetap masalah, tergantung ketersediaan uang untuk membangun fasilitas yag diperlukan. Selain itu, kepemimpinan kepala sekolah, termasuk komitmennya untuk menerima anak cacat di sekolah tersebut. Bahkan masyarakat lokal yang merupakan stake holder sekolah tersebut juga berpengaruh terciptanya pendidikan inklusi. Bahwa ada anak yang sudah duduk di kelas lima sekolah dasar belum mampu mengenal huruf dan menghubungkan huruf menjadi kosa kata dan kata, apalagi membaca kalimat sederhana. ( anak dengan disleksia ). Disleksia merupakan kesalahan pada proses kognitif anak ketika menerima informasi saat membaca. Jika pada anak normal kemampuan membaca sudah muncul sejak usia enam atau tujuh tahun, tidak demikian halnya dengan anak dengan disleksia. Irdamurni , Kasiati, Zulmiyetri dan Johandri Taufan 2018.

Berit H. Johnsen dan Meriam D. Skorten (2003) menyatakan, bahwa prinsip yang disesuaikan dengan sekolah inklusif menyebabkan adanya tuntutan yang besar terhadap guru regular maupun pendidikan khusus.Ini menuntut pergeseran dari tradisi "mengajarkan materi yang sama kepada semua siswa di kelas", menjadi mengajar setiap anak sesuai dengan kebutuhan individualnya tetapi dalam setting kelas. Peserta pelatihan yang terdiri dari 20 orang guru sekolah dasar dan guru sekolah luar biasa pada bulan Agustus tahun 2019, dimana dalam pelatihan mengajak guru SLB dan guru SD saling bekerja sama dalam membantu anak-anak berkebutuhan khusus yang ada di sekolah dasar, dalam bentuk kerjasama dalam melaksanakan identifikasi dan asesmen, pengembangan rencana program pembelajaran (RPP) modifikasi dan pemilihan strategi dan media pembelajaran untuk anak berkebutuhan khusus dalam setting inklusi.

Pelatihan menurut Hadari Nawawi (1997), menyatakan pada dasarnya adalah proses memberikan bantuan bagi para pekerja untuk menguasai keterampilan khusus atau membantu untuk memperbaiki kekurangannya dalam melaksanakan pekerjaan. Fokus kegiatannya adalah untuk meningkatkan kemampuan kerja dalam memenuhi kebutuhan tuntutan cara bekerja yang paling efektif pada masa sekarang. Ernesto A. Franco (1991), mengemukakan pelatihan adalah suatu tindakan untuk meningkatkan pengetahuan dan keterampilan seseorang pegawai yang melaksanakan pekerjaan tertentu. Agar pembelajaran di kelas inklusi berjalan dengan lancar dan tujuan dapat tercapai dengan baik, maka guru-guru harus memiliki kompetensi tentang penyelenggaraan pendidikan inklusif. Pelatihan tentang penyelenggaraan Pendidikan Inklusif bagi SD dan guru SLB merupakan salah satu cara untuk meningkatkan kompetensi guru dalam membelajarkan anak berkebutuhan khusus pada setting inklusi, sehingga anak berkebutuhan 


\section{Suluah Bendang: Jurnal Ilmiah Pengabdian Kepada Masyarakat}

Vol.20, No.1, 2020

Irdamurni , Mega Iswari, Asep A Sopandi, Johandri Taufan, Yarmis Hasan

khusus mendapatkan pendidikan yang layak yang sesuai dengan kebutuhan. Nya di kepulauan Mentawai.

\section{METODE PELAKSANAAN}

Metode Pelaksanaan Iptek bagi masyarakat ini dilaksanakan selama sehari, hari Sabtu tanggal 31 Agustus 2019 di Desa Tua pejat Kecamatan Sipora utara kepulauan Mentawai, yang di hadiri oleh guru sekolah dasar dan guru sekolah luar biasa yaitu guru - guru yang mengajar anak berkebutuhan khusus di kelasnya, baik guru yang mengajar di kelas rendah, maupun guru yang mengajar di kelas tinggi sekolah dasar.

Untuk mencapai tujuan yang ditetapkan sejumlah metode akan digunakan dalam kegiatan ini, metode tersebut sesuai dengan materi yang akan disajikan yaitu : a. Metode ceramah dan tanya jawab dilengkapi dengan media power point untuk menyajikan materi berkaitan dengan hakikat anak berkebutuhan khusus b. Metode cramah, demonstrasi , latihan berkaitan dengan materi tentang tata cara melakukan identifikasi dan asesmen anak berkebutuhan khusus serta pengembangan RPP modifikasi dan PPI pada setting inklusi serta .strategi pembelajaran untuk anak berkebutuhan khusus pada setting inklusi. Hasil akhir guru SD dan guru SLB bekerja sama mengembangkan RPP modifikasi di kelasnya masing masing. Untuk mengetahui berhasil tidaknya pengabdian kepada masyarakat ini dilakukan dengan tanya jawab kepada peserta pelatihan tentang kesulitan yang masih mereka rasakan dalam pelaksanaan pendidikan inklusif.

\section{HASIL DAN PEMBAHASAN}

Hasil penelitian menunjukkan kerjasama antara guru sekolah dasar dan guru sekolah luar biasa dalam penyelenggaraan pendidikan inklusif di kecamatan Sipora utara kepulauan Mentawai terjalin dengan baik dan sukses, begitu juga pengetahuan guru-guru SD tentang penyelenggaraan pendidikan inklusif, yang berhubungan dengan pemahaman tentang hakikat pendidikan inklusif dan hakikat anak berkebutuhan khusus, pemahaman tentang identifikasi dan asesmen anak berkebutuhan khusus, serta pengembangan kurikulum dan perumusan RPP modifikasi di sekolah inklusi serta metoda dan media pembelajaran untuk anak berkebutuhan khusus pada setting inklusi. Hal tersebut di peroleh melalui hasil analisis instrument angket tentang kompetensi guru dalam pelaksanaan pendidikan inklusif. Instrument ini diberikan kepada peserta yang terdiri dari guru sekolah dasar dan guru sekolah luar biasa di kecamatan Sipora Utara. Agar kompetensi guru tentang penyelenggaraan pendidikan inklusif dapat meningkat dan anak aak berkebutuhan khusus dapat terlayani dengan baik.

Unesco 2003 dan UU nomor 20 tahun 2003 tentang Sistem Pendidikan Nasional Pasal 1, menyatakan setiap warga negara mempunyai hak yang sama untuk memperoleh pendidikan yang bermutu, pasal 2 menyatakan, warga negara yang memiliki kelainan fisik, emosional, mental, intelektual, dan/atau sosial berhak memperoleh pendidikan layanan khusus. Selanjutnya berbagai ayat suci Al-Quran juga menyatakan tentang hak anak dan semua makhluk itu sama di sisi Allah, seperti surat At-Tin (ayat 95; 4), berbunyi, " sesungguhnya kami telah menciptakan manusia dalam bentuk sebaik-baiknya". Ayat tersebut menyatakan bahwa Allah menciptakan semua makhluknya baik dan punya potensi, walaupun secara fisik mereka punya kekurangan, tetapi disisi lain mereka punya kelebihan, untuk itu kenapa mereka harus dibedakan. Begitu juga dalam surat An-Nisa' ( 4 -9) berbunyi, "dan hendaklah takut kepada Allah orang-orang yang seandainya meninggalkan di belakang mereka anak-anak yang lemah, dan 
mereka khawatir terhadap (kesejahteraan ) mereka, oleh sebab itu hendaklah mereka mengucapkan perkataan yang benar.

Selanjutnya dalam surat Al-Hujarat ayat 11-13 berbunyi. " hai orang-orang yang beriman, janganlah satu kaum mengolok-olokkan kaum yang lain, (karena) boleh jadi mereka (yang diolok-olokan) lebih baik dari mereka yang mengolok-olokkan. Dari pandangan religius tersebut dapat dimaknai bahwa semua ciptaan Allah itu sama dan mempunyai hak yang sama dalam pendidikan, baik mereka mempunyai kelebihan maupun mereka yang mempunyai kekurangan atau kelainan seperti anak berkebutuhan khusus. Agar anak berkebutuhan khusus terlayani dengan baik, maka guru-guru harus mempunyai kompetensi. Dalam UU RI Nomor 14 tahun 2005 tentang Guru dan Dosen dicantumkan bahwa guru wajib memiliki kompetensi. Kompetensi dimaksud meliputi; (1) kompetensi pedagogik, (2) kompetensi kepribadian, (3) kompetensi sosial, dan (4) kompetensi profesional.

\section{KESIMPULAN}

Paradigma baru yang harus ditanamkan terkait dengan siswa berkebutuhan khusus dalam pendidikan inklusif bahwa sejatinya siswa berkebutuhan khusus adalah siswa normal, akan tetapi memerlukan layanan dan penanganan khusus terkait keistimewaan yang dimiliki. Dalam pembelajaran, diharapkan guru tidak memberikan tuntutan yang sama terkait tagihan kompetensi yang harus dicapai, melainkan disesuaikan dengan kemampuan dan kebutuhan anak. Fleksibilitas ini diperlukan karena sudah sepatutnya anak berkebutuhan khusus di belajarkan dengan tujuan dan layanan khusus. Pendidikan inklusif jangan lagi hanya sekedar charity tapi diharapkan lebih kepada pemenuhan hak belajar bagi semua orang, hanya satu harapan dari orang tua yang memiliki anak berkebutuhan khusus yakni, menyiapkan anak untuk mampu hidup mandiri minimal untuk kompetensi kehidupannya sehari-hari.

\section{DAFTAR PUSTAKA}

CSIE (Centre for Studies on Inclusive Education) (2005), Ten Reasons for Inclusion, http://inclusion.uwe.ac.uk/ csie/10rsns.htm.

Departemen Agama, RI. AL-quran, dan terjemahannya.Semarang :CV.Asy Syifa'

Irdamurni, Kasiyati, Zulmiyetri, Johandri Taufan, 2018. The Effect of Mingle Model to Improve reading Skills for Students With Dyslexia in primary school; Journal of ICSAR, vol 2, no 2, pp 167 - 170 , Juli 2018.

Irdamurni \& Rahmiati 2015. Pendidikan Inklusif Sebagai Solusi dalam Mendidik Anak Istimewa . Jakarta : Paedea

Mulyono Abdulrahman (2003). Landasan Pendidikan Inklusif dan Implikasinya dalam Penyelenggaraan LPTK. Makalah disajikan dalam pelatihan penulisan buku ajar bagi dosen jurusan PLB yang diselenggarakan oleh Ditjen Dikti. Yogyakarta, 26 Agustus 2002.

Margo, A. Mastropieri, 2007. The Inclusive Classroom: Strategies for Effective Instruction. Pearson Education. Inc. Upper Saddle River, New Jersey. Colombus, Ohio.

UNESCO (2003), Conseptual Paper: UNESCO Inclusive Education, a Challenge and a Vision. http://portal.unesco.org/education/en/ev.php.

UNESCO (1994), The Salamanca Statement and Framework for Action on Special Needs Education, World Conference on Special Needs Education: Access and Quality. Paris: UNESCO and the Ministry of Education, Spain. Versi pdf., http://portal.unesco.org/education/en/ev.php. 
Suluah Bendang: Jurnal Ilmiah Pengabdian Kepada Masyarakat

Vol.20, No.1, 2020

Irdamurni , Mega Iswari, Asep A Sopandi, Johandri Taufan, Yarmis Hasan

O'Neil,J. (1995) Can Inclusive Work? A Conversation With James Kauffman and Mara SaponSevin.Educational Leadership 52(4)7-11.

Skjorten, Miriam D.\& Johnsen, Berit H. (ed).( 2003). Pendidikan Kebutuhan Khusus, Sebuah Pengantar. Oslo: Unipub forlag

Undang-undang Nomor 14 tahun 2005 tentang Guru dan Dosen

Undang-undang Nomor 20 tahun 2003 tentang Sistem Pendidikan Nasional.

Peraturan Pemerintah No. 19 tahun 2005 Tentang Standar Nasional Pendidikan 